\title{
Assessment of glycohemoglobin, plasma glucose curve and C-reactive protein as complementary predictors to diagnose prediabetes: a transversal study
}

\author{
Marcelo da Silva Biavaschi", Roberta Schmatz, Jessié Martins Gutierres, Pauline da Costa, Luciane Flores Jacobi, \\ Thabara Campos, Isadora Scaburi, Maria Rosa Chitolina Schetinger, Vera Maria Melchiors Morsch
}

From 20th Brazilian Diabetes Society Congress

Porto Alegre, Brazil. 11-18 November 2015

\section{Background}

The shape of the plasma glucose curve has been considered as a predictor for diabetes in the future, and it could be used to diagnose prediabetes.

\section{Objective}

This study aims to assess the relationship between glycohemoglobin, $\mathrm{C}$-reactive protein (CRP), oxidative stress markers levels and the shape of the plasma glucose curve during the oral glucose tolerance test (OGTT).

\section{Material and methods}

A transversal study was carried out with 59 non-diabetic subjects with increased diabetes risk who underwent an OGTT to analyze glycemia, insulin, glycohemoglobin, lipids, C-reactive protein, malondialdehyde and carbonyl protein. Glycemia was assessed at fasting, 30, 60 and $120 \mathrm{~min}$.

\section{Results}

Overall, 26 individuals had prediabetes, 28 did not have prediabetes (22 had 1h-OGTT>fasting glycemia, 6 had $1 \mathrm{~h}-\mathrm{OGTT} \leq$ fasting glycemia) and 5 had diabetes. The $1 \mathrm{~h}-\mathrm{OGTT} \leq$ fasting glycemia and diabetes groups were excluded, and then a non-parametric test (Mann-Whitney $\mathrm{U}$ test) was used to analyze data. There were no statistical differences between $1 \mathrm{~h}$-OGTT $>$ fasting glycemia and prediabetes groups in the analysis of glycohemoglobin [5.15 (4.8-5.4); 5.20 (5.10-5.4); $\mathrm{p}=0.17$ ], C-reactive protein
[3.70 (1.8-8.9); 3.96 (1.45-7.13); $\mathrm{p}=0.38$ ], lipids and malondialdehyde, but there were differences in fasting, 30, 60 and 120 min glycemia, insulin level [11(8-13); 13(10-18); $\mathrm{p}=0.04]$, Homeostatic Model Assessment-IR [2.45(1.93$2.95) ; 3.30(2.51-5.02) ; \mathrm{p}=0.00]$ and carbonyl protein $[0.48$ (0.42-0.58); 0.57 (0.5-0.76); $\mathrm{p}=0.02$ ].

\section{Conclusions}

These results identify predictors to increased cardiovascular and diabetes risk in individuals without prediabetes and with 1h-OGTT>fasting glycemia, which are similar to predictors in individuals with prediabetes established by the American Diabetes Association criteria.

Published: 11 November 2015

doi:10.1186/1758-5996-7-S1-A153

Cite this article as: da Silva Biavaschi et al:: Assessment of

glycohemoglobin, plasma glucose curve and C-reactive protein as

complementary predictors to diagnose prediabetes: a transversal study.

Diabetology \& Metabolic Syndrome 2015 7(Suppl 1):A153.

* Correspondence: msbiacr@gmail.com

UFSM, Santa Maria, Brazil 